\title{
Recombinant angioarrestin secreted from mouse melanoma cells inhibits growth of primary tumours
}

\author{
Andrzej Smagur, Jarosław Szary and Stanisław Szala ${ }^{\bowtie}$ \\ Department of Molecular Biology, Maria Skłodowska-Curie Memorial Cancer Center and Institute of Oncology, \\ Gliwice Branch, Gliwice, Poland; ${ }^{\circledR}$-mail: sszala@io.gliwice.pl
}

Received: 14 January, 2005; revised: 09 March, 2005; accepted: 31 May, 2005

available on-line: 06 June, 2005

\begin{abstract}
Angioarrestin is a recently described anti-angiogenic protein whose expression is down-regulated in solid tumours of various origins. It has a sequence identical to angiopoietin related protein1. In this study we investigated anti-tumour properties of angioarrestin in B16 (F10) melanoma tumour model. We constructed an expression vector encoding human angioarrestin under the control of EF-1 $\alpha$ promoter. This vector was transferred to B16 (F10) cells and recombinant angioarrestin secreted from the transfected cells was tested for anti-angiogenic activity using endothelial cell proliferation assay. Finally, mice were injected subcutaneously with cells that had been transfected with either angioarrestin-encoding vector or empty vector and tumor growth was compared. The obtained recombinant angioarrestin inhibited proliferation of bovine aortic endothelial cells. Tumours derived from an angioarrestin-secreting B16 (F10) cell clone grew in vivo more slowly than tumours derived from a cell clone transfected with empty vector. These data show, to our knowledge for the first time, that angioarrestin can inhibit primary melanoma tumour growth.
\end{abstract}

Keywords: angioarrestin, anti-angiogenic factor, melanoma

Angiopoietins are recently discovered growth factors specific for endothelial cells (Davis et al., 1996). Although the molecular mechanism through which these proteins regulate angiogenesis has not been fully elucidated, there is ample evidence of their participation in tumour angiogenesis. Various angiopoietins share similar molecular structure; they consist of a signal peptide, a coiled-coil domain enabling oligomerisation (Procopio et al., 1999; Suri et al., 1996) and a C-terminal fibrinogenlike domain which binds to Tie2 receptors (Maisonpierre et al., 1997; Valenzuela et al., 1999). A similar structure has been described for angiopoietin related proteins (ARP1, ARP2 and CDT6). However, these proteins do not bind to Tie2 receptors (Kim et al., 1999; 2000).

Angioarrestin is a recently described anti-angiogenic protein (Dhanabal et al., 2002). It is 491 amino acids long and has a sequence identical to angiopoietin related protein-1 found earlier. The mRNA expression profile of angioarrestin is strikingly down-regulated in tumour tissue, in comparison to matched non-tumour adjacent tissue (Dhanabal et al., 2002). It was also reported that human HT1080 fibrosarcoma cells engineered to ectopically express angioarrestin showed reduced tumourigenicity; after intravenous injection of such cells nude mice showed a marked reduction in the number and size of tumour nodules (Dhanabal et al., 2002). Here, we report an anti-tumour effect of recombinant angioarrestin in syngenic B16 (F10) mouse tumour model. We show that primary melanoma tumours derived from angioarrestin-secreting cells grow more slowly in vivo compared to tumours derived from a cell clone transfected with empty vector.

\section{MATERIALS AND METHODS}

Plasmid construction. A DNA fragment encoding human angioarrestin was obtained by PCR with liver cDNA as a template. The cDNA was synthesized using M-MLV reverse transcriptase (Invitrogen, San Diego, CA, USA), oligo-dT primer and

Abbreviations: BAE cells, bovine aortic endothelial cells; bFGF, basic fibroblast growth factor; M-MLV, Moloney murine leukemia virus; VEGF, vascular endothelial growth factor. 
human foetal liver total RNA template (Stratagene, La Jolla, CA, USA). For PCR Platinum Pfx polymerase (Invitrogen) and the following oligonucleotide primers were used: downstream 5'-TTT TTA GAT CTA AAA TGA AGA CTT TTA CCT GGA C-3' and upstream 5'-AAA AAG CTA GCA GGC TTG ATC ATC ATC TGA ACT-3'. The downstream and upstream primers were designed to include BglII and NheI sites, respectively. The amplified fragments were digested with $B g l \mathrm{II}$ and NheI and ligated into pEF1/V5-HisA expression vector (Invitrogen, Carlsbad, CA, USA) digested with BamHI and XbaI. The pEF1/V5-HisA plasmid contains the promoter from human elongation factor- $1 \alpha$ gene. The resultant recombinant protein is tagged at its C-terminus with both V5 epitope and a 6His fragment.

The inserts' nucleotide sequence was confirmed by sequencing using ABI PRISM ${ }^{\mathrm{TM}}$ Big Dye Terminator Cycle Sequencing Ready Reaction Kit with Ampli Taq Polymerase (Applied Biosystems, Foster City, CA, USA). Both insert strands were sequenced and the obtained sequence was compared to the sequence NM_004673 from GenBank. No mutation or polymorphisms were found.

Transfection and preparation of cell-conditioned medium. B16 (F10) murine melanoma cells (from American Type Culture Collection, Rockville, MD) were cultured in RPMI 1640 medium supplemented with $10 \%$ foetal calf serum (ICN Pharmaceuticals, Irvine, CA, USA). The plasmid pEF1/V5-HisA/ ARR or pEF1/V5-HisA parental plasmid were transfected into B16 (F10) cells using Lipofectamine 2000 (Invitrogen, Carlsbad, CA, USA) according to the manufacturer's protocol. Transfectants were selected and grown in medium containing G418 (1 mg/mL). One of the clones transfected with the angioarrestinencoding vector and one clone with empty vector were used in further experiments. Cells were plated at a density of $5 \times 10^{3} /$ well of a 24 -well culture dish. At various time-points after plating (24, 48 and $72 \mathrm{~h}$ ) cells were incubated with MTT (3-(4, 5-dimethylthiazol-2-yl)-2, 5-diphenyltetrazolium bromide) from Sigma (St. Louis, MO, USA). The resulting formazan was solubilised with $0.04 \mathrm{M} \mathrm{HCl}$ in isopropanol and absorbance was determined at $570 \mathrm{~nm}$ using a microplate absorbance reader. Conditioned medium was collected from parental B16 (F10) cells and stably transfected cell clones grown in T-75 bottles (NUNC, Wiesbaden, Germany). Sub-confluent cells were washed with RPMI 1640 without serum and were incubated in this medium for $48 \mathrm{~h}$. Cell-conditioned medium was collected, centrifuged to remove cell debris and stored at $-70^{\circ} \mathrm{C}$ until use. The medium was then concentrated and desalted with de-ionized water using Ultrafree-15 centrifugal filter device 10000 MWCO (Millipore Co., Bedford, MA, USA). Protein concentration was determined using
Bio-Rad protein microassay kit (Bio-Rad, Hercules, CA, USA).

Western blot. Samples of concentrated media conditioned by parental and stably transfected B16 (F10) cells were electrophoresed in $8 \%$ polyacrylamide gel containing SDS and transferred onto nitrocellulose membrane (Schleicher \& Schuell, Germany). The membrane was incubated in a blocking buffer (TBS/3\% skim milk) for $1 \mathrm{~h}$ at room temperature and then incubated at $4^{\circ} \mathrm{C}$ overnight with monoclonal antibodies against V5 epitope (Invitrogen, Carlsbad, CA) diluted 1:5000 with TBS/3\% skim milk. On the following day the membrane was washed four times with TBS $/ 0.1 \%$ Tween 20 and then incubated for 75 $\mathrm{min}$ at room temperature with horse anti-mouse IgG biotin conjugate (Vector Laboratories, Burlingame, CA, USA) diluted 1:200 with TBS/1\% skim milk. After four washes in TBS the membrane was incubated for $60 \mathrm{~min}$ at room temperature with streptavidin biotinylated horseradish peroxidase complex (Amersham, Ayelesbury, UK) diluted 1:1000. The peroxidase substrate used for band staining was 3,3'-diaminobenzidine tetrahydrochloride (Sigma, St. Louis, MO, USA).

Endothelial cell proliferation assay. The assay was performed as described previously (Wilczyńska et al., 2001). Briefly, $5 \times 10^{3}$ BAE cells per well of gelatinized 24-well plate were plated in RPMI/5\% fetal calf serum (FCS) and incubated for $2 \mathrm{~h}$. The medium was replaced with $0.5 \mathrm{ml}$ fresh RPMI containing $2 \%$ FCS and samples of concentrated conditioned media. After 1-h incubation $0.5 \mathrm{ml}$ medium containing 2\% FCS and $10 \mathrm{ng} / \mathrm{ml}$ bFGF (R\&D Systems, Minneapolis, MN, USA) was added. After $72 \mathrm{~h}$ the number of living cells was quantified using MTT assay.

Animal studies. Six- to eight-week-old C57B1/6 mice (females) had their left dorsal side shaved and were inoculated subcutaneously with B16 (F10) cells. To assess the in vivo growth of stably transfected B16 (F10) cell clones, mice were injected with $5 \times$ $10^{5}$ cells (per animal) containing either the pEF1/V5HisA/ARR plasmid or the pEF1/V5-HisA parental plasmid. Cells were suspended in $100 \mu \mathrm{l}$ of phosphate buffered saline (PBS) without $\mathrm{Ca}^{2+}$ and $\mathrm{Mg}^{2+}$. Tumours were measured with a caliper gauge three times a week. Tumour volume was calculated from the following formula: Tumour Volume $=(\text { Width })^{2} \times$ Length $\times 0.52$.

\section{RESULTS}

A cDNA fragment encoding angioarrestin was cloned into pEF1/V5-HisA expression vector under the transcriptional control of elongation factor- $1 \alpha$ promoter (Mizushima \& Nagata, 1990; Salomon et al., 2000). The recombinant protein was tagged with 
V5 epitope and 6xHis fragment. Using Western blot we obtained two protein bands about 60 and about $64 \mathrm{kDa}$ under reducing conditions and 3 bands about 130 , about 180 and about $220 \mathrm{kDa}$ under non-reducing conditions (Fig. 1). Our data suggest that recombinant angioarrestin is secreted from transfected B16 (F10) cells as disulphide-linked multimers.

To confirm the anti-angiogenic properties of recombinant angioarrestin we performed endothelial cell proliferation assay. Statistically significant inhibition of BAE cell proliferation was observed when cells were treated with concentrated media from angioarrestin-secreting cells when compared to media conditioned by empty vector transfected cells (Fig. 2). The effect is dose-dependent. The highest dose (350 $\mu \mathrm{g}$ of protein/ml medium) gives a $61 \%$ inhibition. These data indicate that the obtained recombinant angioarrestin significantly inhibits bFGFstimulated proliferation of endothelial cells.

Tumours derived from an angioarrestin-secreting B16 (F10) cell clone grew more slowly in vivo than tumours derived from a cell clone transfected with empty pEF1/V5-HisA vector (Fig. 3A). However, the in vitro proliferation rate of these clones was equal (Fig. 3B). A statistically significant difference in primary tumour growth was observed starting from the 15th day of the experiment $(P<0.04$; Mann-Whitney $U$-test). There were no statistically significant differences between the control groups. These data indicate that human angioarrestin se-

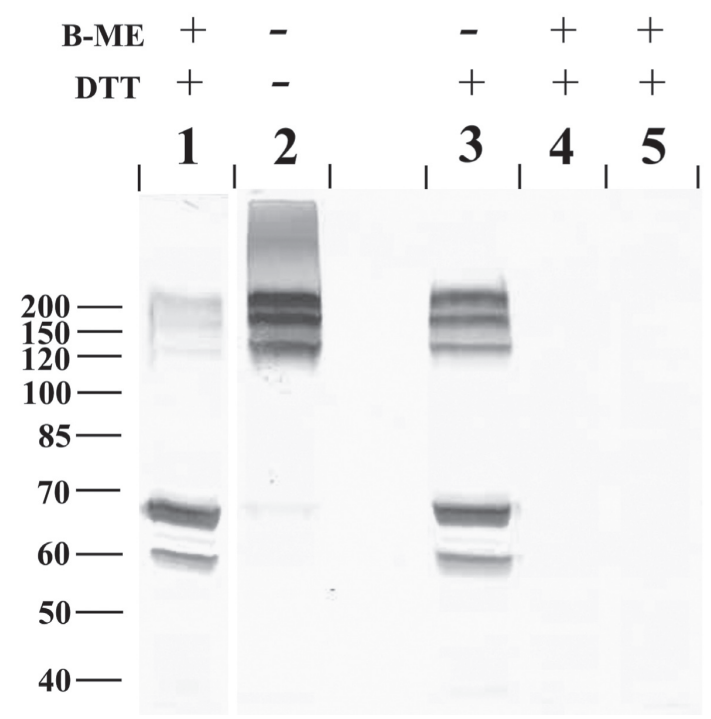

Figure 1. Identification of angioarrestin secreted by stably transfected B16 (F10) cells (Western blot).

An aliquot of concentrated conditioned medium $(10 \mu \mathrm{g}$ of total protein) was electrophoresed under non-reducing conditions or in loading buffer containing $75 \mathrm{mM}$ dithiothreitol (DTT) and/or 2.5\% $\beta$-mercaptoethanol (B-ME). Proteins were electrophoresed and immunoblotted with monoclonal antibodies against V5 epitope. Lanes 1, 2, 3, B16 (F10)/pEF1/V5-HisA/ARR; lane 4, B16 (F10)/pEF1/V5HisA; lane 5, non-transfected B16 (F10). creted from transfected B16 (F10) cells significantly inhibits growth of primary melanoma tumours.

\section{DISCUSSION}

We show that recombinant human angioarrestin tagged with $\mathrm{V} 5$ and $6 x$ His epitopes is secreted from transfected B16 (F10) cells as disulphide-linked dimers. Similar results were shown for angioarrestin expressed in human HT1080 fibrosarcoma cells (Dhanabal et al., 2002). Under reducing conditions we also obtained two bands of monomer protein (about 60 and about $64 \mathrm{kDa}$ ). This can be a result of alternative posttranslational modification of angioarrestin. Analysis of angioarrestin amino-acid sequence using NetNGlc 1.0 software revealed that angioarrestin contains two sites of potential N-glycosylation but only one of these sites is predicted to be N-glycosylated with high $(77 \%)$ probability. Under non-reducing conditions we observed three high molecular mass bands (about 130, about 180 and about $220 \mathrm{kDa}$ ). Most probably, the about $130 \mathrm{kDa}$ protein is a disulphide-linked dimer (Dhanabal et al., 2002). The bands about 180 and about $220 \mathrm{kDa}$ may be tri- and tetramers (Procopio et al., 1999; Peek et al., 2002) or may result from angioarrestin binding by other proteins present in conditioned media.

Dhanabal et al. (2002) have reported that angioarrestin blocks VEGF/bFGF-mediated endothelial cell proliferation, migration, tube formation and adhesion to extracellular matrix proteins. Using the pooled transfected HT1080 cells they also demonstrated that ectopic expression of angioarrestin inhibited tumour nodule formation. In our animal study tumours derived from angioarrestin-transfected B16 (F10) cells were significantly smaller (in-

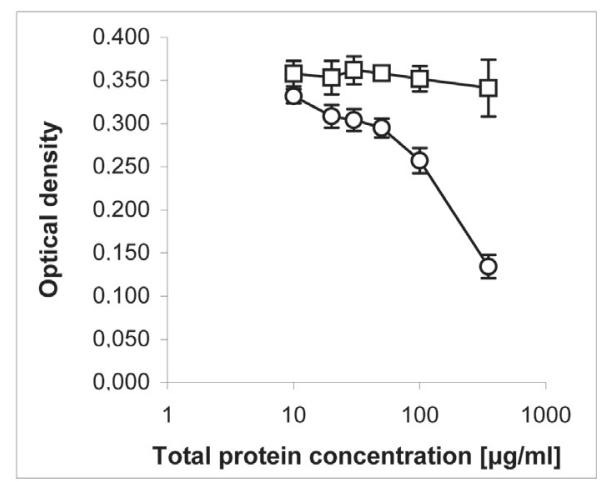

Figure 2. Inhibition of bFGF-induced proliferation of bovine aortic endothelial (BAE) cells.

BAE cells were grown in media containing concentrated proteins secreted by B16(F10) cell clones transfected with pEF1/V5-HisA/ARR (O) or pEF1/V5-HisA empty vector ( $\square)$. Cell proliferation was quantified by the MTT assay. Results are shown as means of triplicate wells \pm S.D. $(P<0.05$ Mann-Whitney $U$-test $)$. 
hibition of tumour growth was from $40 \%$ up to $60 \%$ when compared with control). The proliferation rate in vitro of both transfected cell clones was identical. In addition, we did not observe increased survival time in the group of mice injected with angioarrestin-secreting cells, compared to control. However, in vitro transfer of angioarrestin cDNA into B16 (F10) cells reduces tumour growth but does not produce dormancy of the primary melanoma tumours. We obtained similar results previously using renal carcinoma cells transfected with mouse endostatin (Szary \& Szala, 2001). Probably, the level of angioarrestin

A

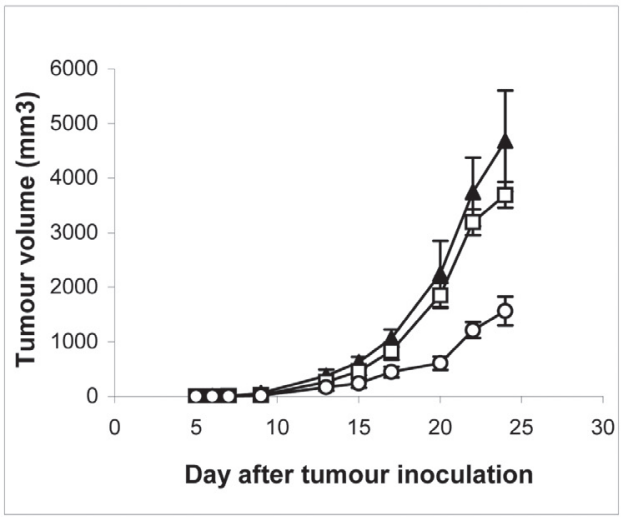

B

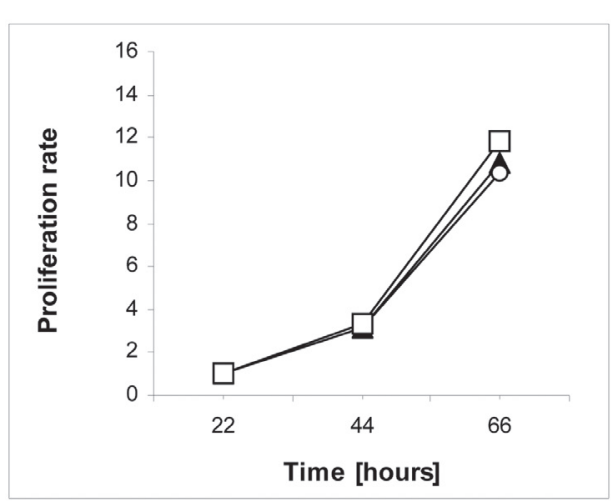

Figure 3.

A. Tumour growth in syngenic mice injected with angioarrestin-transfected cells $(O)$, empty vector-transfected cells ( $\square)$, or parental B16 (F10) cells (A)

All experimental groups consisted of six mice. Values represent mean tumour volume \pm S.D. The difference between tumour volumes in both groups was statistically significant from day 15 of the experiment $(P<0.04$ Mann-Whitney $U$-test). These are representative results from one out of two experiments.

B. In vitro proliferation rate of B16 (F10) cell clone stably transfected with empty pEF1/V5-HisA ( $\square$ ), pEF1/V5-HisA/ ARR vector $(O)$ or parental B16(F10) cells $(\Delta)$.

The number of cells after $22 \mathrm{~h}$ was taken as one unit. The proliferation rate shown is the mean of quadruplicate samples. The S.D. never exceeded $5 \%$ of the reported values. There were no statistically significant differences between these groups (Mann-Whitney U-test). expression is not sufficient to completely arrest primary tumour growth; this might be related to the loss of the transgene during tumour growth and/or promoter methylation. It is also possible that as primary tumour grows VEGF secretion from tumour cells and macrophages (Brown et al., 1997; Damert et al., 1997) induced by hypoxia may oppose the antiangiogenic effect of angioarrestin. Hypoxia induces also overexpression of VEGF receptor gene (Forsyte et al., 1996) and this phenomenon is important for growth and metastases of melanoma tumours (Rofstad \& Danielsen, 1998).

In summary, our data confirm the anti-angiogenic and anti-tumour activity of angioarrestin.

\section{Acknowledgements}

This work was supported by a grant from the State Committee for Scientific Research (KBN, Poland) No. 6 P05A 06221.

We thank Helena Paterak and Małgorzata Krawczyk for excellent technical assistance; Dr. Aleksander Sochanik for reviewing the article; Jolanta Pamuła and Renata Cyplińska for help in plasmid sequencing.

\section{REFERENCES}

Brown LF, Detmar M, Claffey K, Nagy JA, Feng D, Dvorak AM, Dvorak HF (1997) Vascular permeability factor/ vascular endothelial growth factor: a multifunctional angiogenic cytokine. EXS 79: 233-269.

Damert A, Ikeda E, Risau W (1997) Activator-protein-1 binding potentiates the hypoxia-inducible factor-1-mediated hypoxia-induced transcriptional activation of vascular-endothelial growth factor expression in C6 glioma cells. Biochem J 327: 419-423.

Davis S, Aldrich TH, Jones PF, Acheson A, Compton DL, Jain V, Ryan TE, Bruno J, Radziejewski C, Maisonpierre PC, Yancopoulos GD (1996) Isolation of angiopoietin-1, a ligand for the TIE2 receptor, by secretion-trap expression cloning. Cell 87: 1161-1169.

Dhanabal M, LaRochelle WJ, Jeffers M, Herrmann J, Rastelli L, McDonald WF, Chillakuru RA, Yang M, Boldog FL, Padigaru M, McQueeney KD, Wu F, Minskoff SA, Shimkets RA, Lichenstein HS (2002) Angioarrestin: an antiangiogenic protein with tumor-inhibiting properties. Cancer Res 62: 3834-3841.

Forsythe JA, Jiang BH, Iyer NV, Agani F, Leung SW, Koos RD, Semenza GL (1996) Activation of vascular endothelial growth factor gene transcription by hypoxia-inducible factor 1. Mol Cell Biol 16: 4604-4613.

Kim I, Moon SO, Koh KN, Kim H, Kwak HJ, Koh GY (1999) Molecular cloning, expression and characterization of angiopoietin-related protein. J Biol Chem 274: 26523-2658.

Kim I, Kim HG, Kim H, Kim HH, Park SK, Uhm CS, Lee ZH, Koh GY (2000) Hepatic expression, synthesis and secretion of novel fibrinogen/angiopoietin-related protein prevents endothelial cell apoptosis. Biochem J 346: 603-610. 
Maisonpierre PC, Suri C, Jones PF, Bartunkova S, Wiegand SJ, Radziejewski C, Compton D, McClain J, Aldrich TH, Papadopoulos N, Daly TJ, Davis S, Sato TN, Yancopoulos GD (1997) Angiopoietin-2, a natural antagonist for Tie2 that disrupts in vivo angiogenesis. Science 277: 55-60.

Mizushima S, Nagata S (1990) pEF-BOS, a powerful mammalian expression vector. Nucleic Acids Res 18: 5322.

Peek R, Kammerer RA, Frank S, Otte-Holler I, Westphal JR (2002) The angiopoietin-like factor cornea-derived transcript 6 is a putative morphogen for human cornea. $J$ Biol Chem 277: 686-693.

Procopio WN, Pelavin PI, Lee WM, Yeilding NM (1999) Angiopoietin-1 and -2 coiled coil domains mediate distinct homo-oligomerization patterns, but fibrinogenlike domains mediate ligand activity. J Biol Chem 274: 30196-30201.

Rofstad EK, Danielsen T (1998) Hypoxia-induced angiogenesis and vascular endothelial growth factor secretion in human melanoma. Br J Cancer 77: 897-902.

Salomon P, Kindler V, Ducrey O, Chapuis B, Zubler RH, Trono D (2000) High-level transgene expression in human hematopoietic progenitors and differentiated blood lineages after transduction with improved lentiviral vectors. Blood 96: 3392-3398.

Suri C, Jones PF, Patan S, Bartunkova S, Maisonpierre PC, Davis S, Sato TN, Yancopoulos GD (1996) Requisite role of angiopoietin-1, a ligand for the TIE2 receptor, during embryonic angiogenesis. Cell 87: 1171-1180.

Szary J, Szala S (2001) Intratumoral administration of naked plasmid DNA encoding mouse endostatin inhibits renal tumor growth. Int J Cancer 91, 835-839.

Valenzuela DM, Griffiths JA, Rojas J, Aldrich TH, Jones PF, Zhou H, McClain J, Copeland NG, Gilbert DJ, Jenkins NA, Huang T, Papadopoulos N, Maisonpierre PC, Davis S, Yancopoulos GD (1999) Angiopoietins 3 and 4: diverging gene counterparts in mice and humans. Proc Natl Acad Sci USA 96: 1904-1909.

Wilczyńska U, Kucharska A, Szary J, Szala S (2001) Combined delivery of antiangiogenic protein (angiostatin) and immunomodulatory gene (interleukin-12) in the treatment of murine cancer. Acta Biochim Polon 48: $1077-10784$ 